\title{
Some Ultrastructural Features of Micronuclei during Conjugation and Autogamy in Paramecium aurelia
}

\author{
By A. JURAND \\ Institute of Animal Genetics, The University, Edinburgh EH9 $3 J \mathrm{~N}$
}

(Received 18 August 1975)

\begin{abstract}
SUMMARY
Micronuclei of Paramecium aurelia at the prophase (crescent stage) of the first meiotic division during conjugation or autogamy were characterized by an elongated, somewhat curved shape. They contained small aggregates of a fibrillar material scattered uniformly throughout the nucleoplasm and a single layer of intranuclear microtubules located close under, and adhering to, the inner nuclear membrane. These microtubules ran parallel to each other and parallel to the long axis of the micronucleus. At one end of the crescent stage micronuclei, there were two electron-dense bodies, which may function as organizing centres for microtubular assembly. During subsequent meiotic divisions the single layer of intranuclear microtubules was absent but a microtubular meiotic spindle was present.

Both gamete pronuclei in each conjugant contained microtubules distributed evenly throughout the nucleoplasm and aligned in one direction. The migratory (male) pronucleus formed pseudopodia during its passage through the cytoplasmic bridge and was surrounded by extranuclear bundles of microtubules located in the cytoplasm close to the nuclear envelope. Stationary (female) pronuclei had no extranuclear microtubules.

During all stages of conjugation or autogamy the nuclear envelope remained intact.
\end{abstract}

\section{INTRODUCTION}

Ultrastructural investigations of the cytology of conjugation in the genus Paramecium have been carried out by Vivier \& André (I96I), André \& Vivier (1962), Schneider (I963), Inaba, Imamoto \& Suganuma (1966) and by Stevenson (1972). Interphase micronuclei in vegetative clones of Paramecium aurelia, and their mitosis during the binary fission, have been investigated at the ultrastructural level (Jurand \& Selman, 1970, Stevenson \& Lloyd, 1971); and Inaba \& Kudo (1972) reported observations on the division of both the microand macronucleus of Paramecium micronucleatum.

Jurand \& Selman (1969) summarized the order of events and the approximate duration of the consecutive stages of conjugation for $P$. aurelia. Meiosis takes place within the first $4 \mathrm{~h}$ after formation of pairs, and after two rapid meiotic divisions of both micronuclei eight haploid micronuclei are formed. In the next $\mathrm{I} \frac{1}{2}$ to $2 \mathrm{~h}$ only one of these haploid micronuclei survives and the other seven begin to degenerate. The surviving micronucleus then divides mitotically (third pregamic division) to form two gamete pronuclei, one called the stationary or female pronucleus and the other the migratory or male pronucleus.

This paper compares the ultrastructure of the micronuclei at the prophase of the first pregamic division (crescent stage micronuclei), at the second pregamic division in conjugation and autogamy, and of the gamete pronuclei at the time of exchange of the migratory nuclei during conjugation. 


\section{METHODS}

Conjugating pairs of $P$. aurelia consisted mainly of individuals of the mating type VII of a mutant of stock 5IS (syngen 4) called 'pawn' and individuals of the mating type VIII of a nondischarge mutant, also of stock 5IS. Additional observations were made on conjugating pairs from stock 3 I (syngen 8 ) and occasionally from other stocks of this species. Corresponding mating types grown as mass cultures at $27^{\circ} \mathrm{C}$ were mixed and pairs were isolated and fixed individually after $3,4,5$ and $5 \frac{1}{2} \mathrm{~h}$. In addition to these individual pairs, the conjugating mass cultures were fixed in bulk after the same time intervals. Two mass cultures were also fixed after 6 and $6 \frac{3}{4} \mathrm{~h}$ of conjugation without isolation of pairs.

For comparative studies on the ultrastructure of the micronuclei during autogamy, stock 5 IS of $P$. aurelia was used. Cultures were grown at $27^{\circ} \mathrm{C}$ for to days (about 30 fissions) with excess of food, and then concentrated and transferred to the maintenance solution (Dryl, 1959). Samples were tested for autogamy at intervals of $2 \mathrm{~h}$ by staining with $\mathrm{I} \%$ $(\mathrm{w} / \mathrm{v})$ methyl green in $5 \%(\mathrm{v} / \mathrm{v})$ acetic acid. After $\mathrm{I} 6 \mathrm{~h}$, when about $80 \%$ of the animals were in autogamy, paramecia were concentrated, fixed and embedded.

Fixation was usually in $\mathrm{I} \%(\mathrm{w} / \mathrm{v}) \mathrm{OsO}_{4}$ (Jurand \& Selman, 1969). In other cases, fixation with $2 \%(\mathrm{w} / \mathrm{v})$ glutaraldehyde solution in $0.05 \mathrm{M}$-cacodylate buffer for $\mathrm{I} h$ at room temperature (about $18{ }^{\circ} \mathrm{C}$ ) was followed by a buffer rinse and post-fixation with $\mathrm{OsO}_{4}$ as above. The material was then embedded in Araldite using a slow rotary shaker,(Jurand \& Ireland, 1965).

Blocks with single conjugating pairs were serially sectioned in planes passing through both conjugants. The mass cultures of conjugating pairs and autogamous animals were sectioned at random. Ultra-thin sections were mounted on grids coated with collodioncarbon films. Sections from material fixed with $\mathrm{OsO}_{4}$ were stained with $2.5 \%(\mathrm{w} / \mathrm{v})$ uranyl acetate in $\mathrm{I} \%(\mathrm{w} / \mathrm{v}) \mathrm{KMnO}_{4}$. Sections from material fixed in glutaraldehyde followed by $\mathrm{OsO}_{4}$ were stained with $5 \%(\mathrm{w} / \mathrm{v})$ uranyl acetate followed by lead citrate (Reynolds, 1963).

The most suitable material for observations on the ultrastructure of micronuclei at the prophase (crescent) stage of the first meiotic division were the individual pairs fixed after known conjugation times, and conjugating mass cultures fixed $3 \mathrm{~h}$ from the onset of conjugation. In mass cultures fixed after 4 and $5 \mathrm{~h}$, the crescent stage was found in some conjugants which were delayed in pair formation. For the second meiotic division and its products, single pairs or mass cultures fixed after 4,5 and $5 \frac{1}{2} \mathrm{~h}$ were used. For the observations on the gamete pronuclei, mass cultures of conjugating pairs were examined after $5 \frac{1}{2}, 6$ and $6 \frac{3}{4} \mathrm{~h}$ from the onset of conjugation.

\section{RESULTS}

\section{Crescent stage}

In single pairs and in mass cultures fixed $3 \mathrm{~h}$ after the onset of conjugation, most of the micronuclei had markedly elongated structures (up to $20 \mu \mathrm{m}$ in length) of crescent or sickle shape. In longitudinal sections, longitudinally running folds sometimes caused the profiles of the crescent stage micronuclei to appear to consist of interconnected parallel parts of an overall crescent shape. This stage corresponded with the prophase of the first meiotic division. The number of crescent-shaped micronuclei never exceeded two. They did not contain a central region of condensed chromatin, characteristic of the vesicular interphase micronuclei of vegetative cells, nor did they show the presence of condensed chromosomes: in ultra-thin sections, their contents appeared to consist of uniformly scattered small loose aggregates of microfibrils (Fig. I). 
The most striking feature of the crescent stage nuclei were the microtubular elements located as a single layer under the nuclear envelope. These microtubules ran parallel to each other and parallel to the long axis of the elongated micronuclei. The midpoint-to-midpoint distance between adjacent microtubules was fairly constant, with a mean of $42 \mathrm{~nm}$.

In transverse sections, these micronuclei appeared amoeboid in shape with many arms, due to the presense of longitudinally running folds (Fig. 2). In this plane the microtubular elements were noticeable as round, regularly spaced structures, with a mean diameter of $24 \mathrm{~nm}$, close to the inner nuclear membrane. Occasionally a few single microtubules were found deeper in the nucleoplasm, away from the nuclear envelope (Fig. 3). The average number of subunits in transverse sections was 13 , the same as is commonly found in microtubules of various origin (Roberts, 1974). In tangential sections through the nuclear envelope, the microtubules formed a sheet of parallel units, which appeared and disappeared depending on the curvature of the nuclear envelope (Fig. 4). There was no indication of any lateral bridge connections or any other material between adjacent microtubules.

At one end of the crescent stage micronucleus, serial thin sections showed two electrondense round and hollow structures, $0.2 \mu \mathrm{m}$ in diameter. These lay inside the micronucleus, very close to the inner nuclear membrane and at the level of the sheet of microtubules (Figs. 5 and 6). They resembled the spherical condensation forms of centrioles described by Dirksen \& Crocker (1966), but differed in not consisting of nine triplets of short segments of microtubules.

\section{Later stages of meiosis}

In single pairs and in mass cultures of conjugating pairs after $4 \mathrm{~h}$, some micronuclei were in prophase of the second meiotic division (Fig. 7), or even at later stages, showing chromosomes arranged either in metaphase plates or in telophase configurations or with the chromosomes scattered throughout the whole profile of the micronucleus. The appearance depended on the stage of division and, to some extent, the plane of the section (Figs. 8, 9 and 1o). The spindle of these stages consisted of microtubules virtually identical with those in the mitotic spindle. Their average diameter was about $2 \mathrm{I} \mathrm{nm}$, slightly less than the diameter of microtubules in the crescent stage micronuclei. At metaphase and anaphase, the chromosomes appeared to be attached to microtubules of the spindle at centromeric regions. Other microtubules ran unattached between the chromosomes as continuous interzonal microtubules. Centrioles have not been found in meiotic micronuclei.

The shape of the meiotic micronuclei, i.e. before the third pregamic division, depended on the phase of the division. At metaphase they were ovoid or spindle shaped and at telophase elongated or dumbbell shaped. Their diameter varied, but they were approximately $5 \times 8 \mu \mathrm{m}$ at metaphase and $5 \times 14 \mu \mathrm{m}$ at anaphase and telophase. The nuclear envelope of these micronuclei remained intact at all times and was of the usual type consisting of outer and inner membranes with regularly spaced nuclear pores, $120 \mathrm{~nm}$ from each other. The micronuclei at this stage were regarded as meiotic because all were of the same type in conjugants fixed after $4 \mathrm{~h}$ of conjugation, and because up to five (out of eight) almost identical nuclei have been observed in one thin section. They were always rather deep in the cytoplasm and close to the macronucleus.

\section{Gamete pronuclei}

In experiments with conjugating pairs in mass cultures fixed $5 \frac{1}{2}, 6$ and $6 \frac{3}{4} \mathrm{~h}$ after the beginning of conjugation, one or both gamete pronuclei were usually located in the paroral region (Fig. II). In general, they did not differ significantly from interphase micronuclei. However, the core of the condensed chromatin was less compact and the granular zone less 

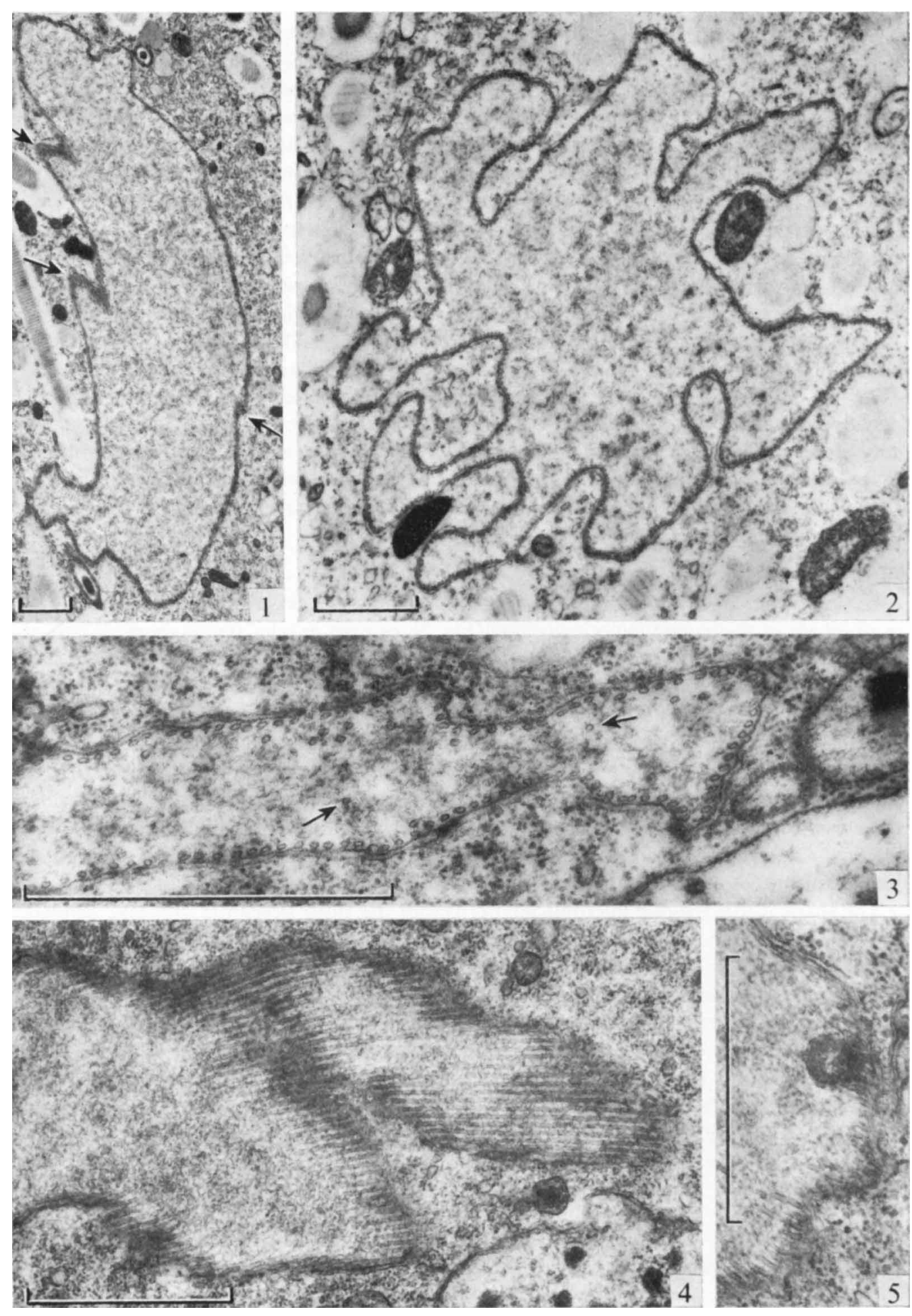

Figs. I-5. For legend see facing page. 


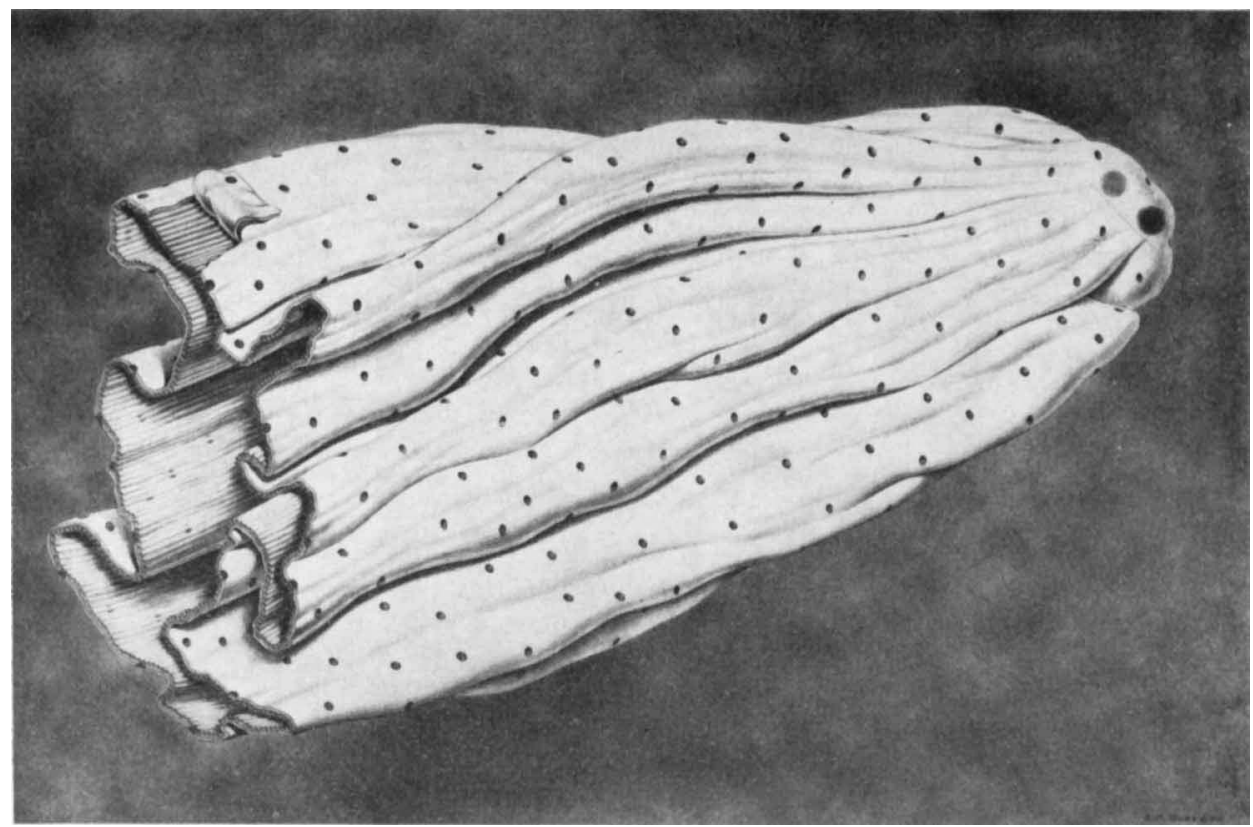

Fig. 6. A diagrammatic three-dimensional reconstruction of a transversely-sectioned crescent stage micronucleus at approximately a quarter of its length from the end with the microtubule condensation centres. The reconstruction summarizes Figs. $I$ to 5 and is based on numerous other micrographs.

obvious. Both stationary and migratory gamete pronuclei contained numerous parallel microtubules scattered in the achromatic area of low electron density (Figs. I 2 and I3).

Just outside the nuclear envelope of the migratory gamete pronuclei were rather short microtubular elements, either singly or in small bundles (Fig. 14). No such elements were found in the vicinity of the stationary gamete pronuclei or in the cytoplasm further away from the micronuclei at this stage. At the time of passage through the cytoplasmic bridge between two conjugating partners, the nuclear envelope of the migratory gamete pronucleus

All bar markers represent I $\mu \mathrm{m}$. Fixatives used were: Figs. I and 2, I $\%(w / v)$ osmium tetroxide;

Figs. 3, 4 and $5,2.5 \%(w / v)$ glutaraldehyde followed by osmium tetroxide.

Fig. I. Nearly longitudinal section through a crescent stage micronucleus in a conjugant $3 \mathrm{~h}$ after the beginning of conjugation. Note the obliquely sectioned longitudinal ridges (arrowed) and almost homogeneous nucleoplasm.

Fig. 2. Transverse section through a crescent stage micronucleus in a conjugant as in Fig. I. In this projection, longitudinal ridges appear as pseudopodial appendages. Note the sheet of microtubules adhering to the inner nuclear membrane. The nucleoplasm shows uniformly scattered aggregates of microfibrillar material.

Fig. 3. Transverse section through a longitudinal ridge of a crescent stage micronucleus at higher magnification. Note the transversely sectioned microtubules adhering to the inner nuclear membrane. There are also a few microtubules situated deeper in the nucleoplasm (arrowed).

Fig. 4. Tangential section through the nuclear envelope of a crescent stage micronucleus in a conjugant $3 \mathrm{~h}$ after the beginning of conjugation. Note the microtubules running parallel to each other and appearing and disappearing from the section according to the undulations of the nuclear envelope.

Fig. 5. Longitudinal section through the extreme end of a crescent stage micronucleus showing an electron-dense hollow body $0.2 \mu \mathrm{m}$ in diameter surrounded by microtubules: 

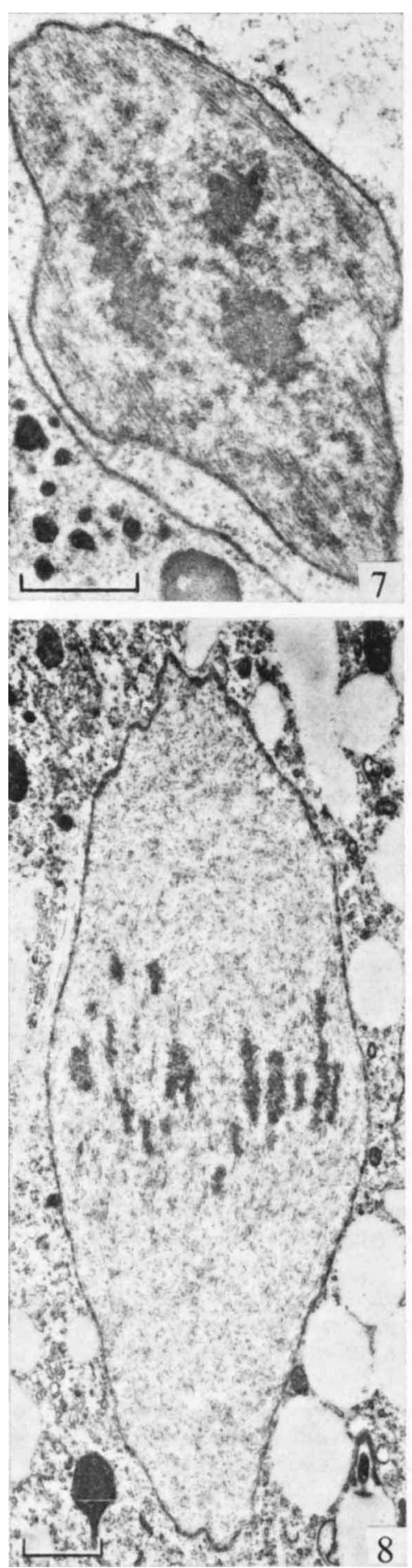

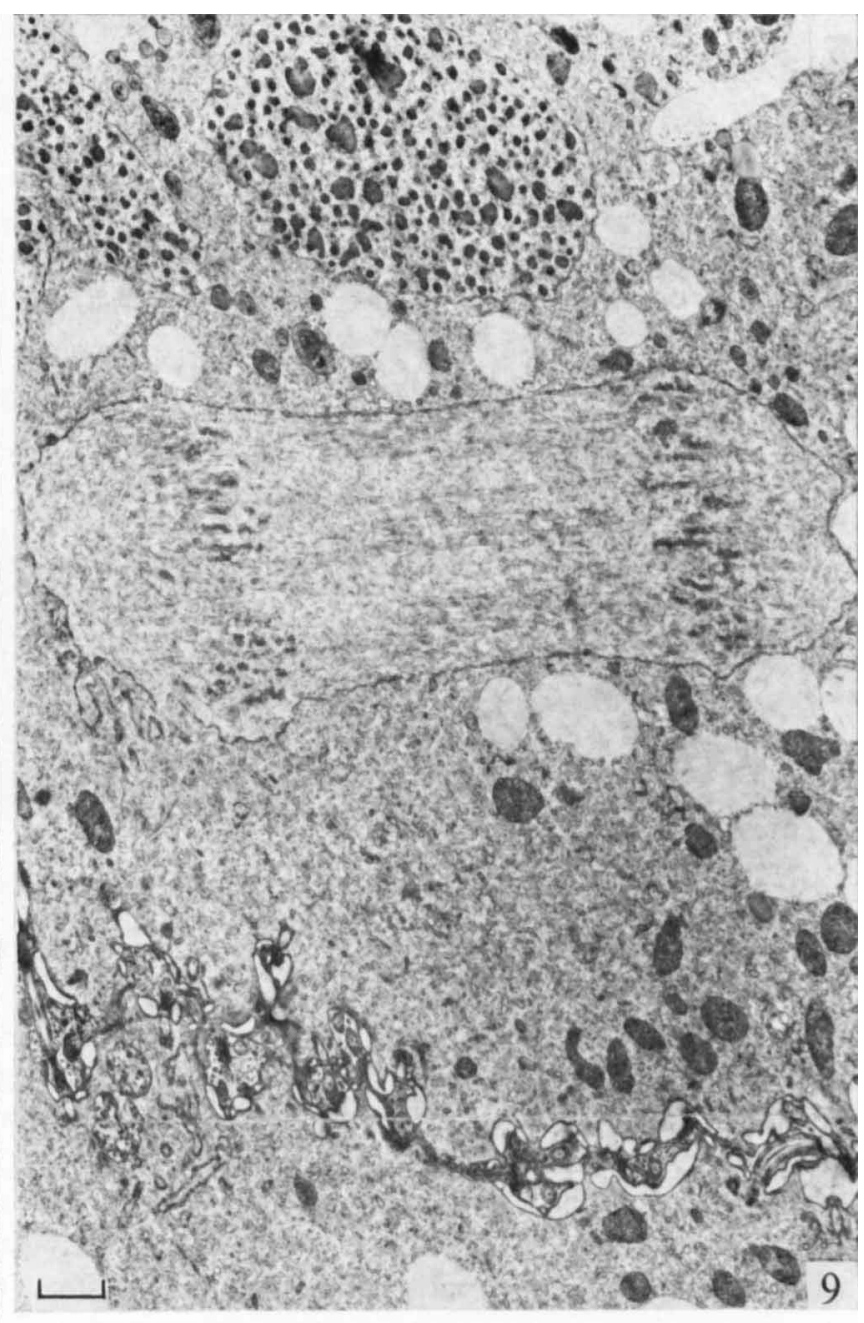

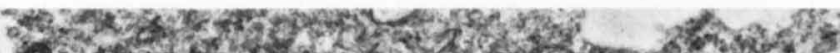

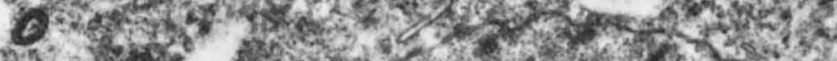

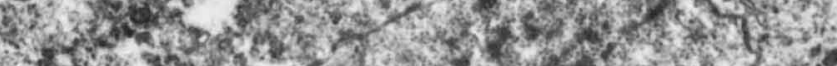

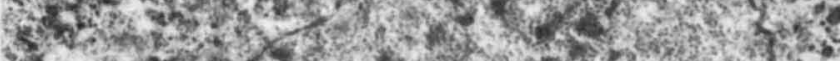

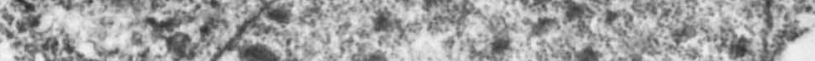

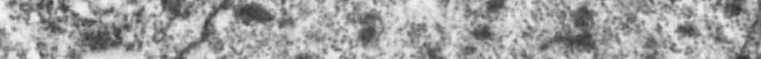

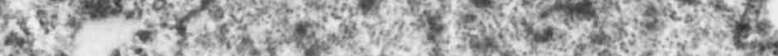

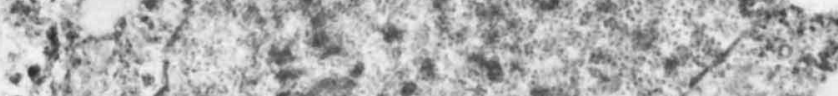

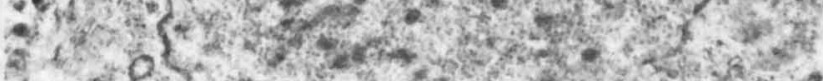

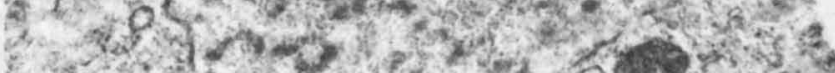

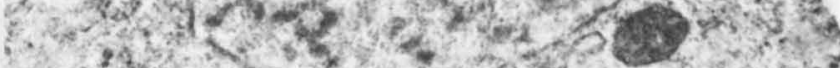

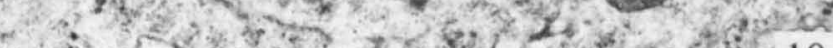

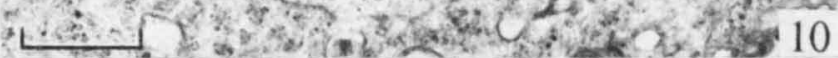

Figs. 7-10. For legend see facing page. 
formed discrete pseudopodia at one end of the pronucleus and in the adjacent cytoplasm there were microtubular elements and possibly microfilaments (Fig. 15).

\section{Autogamy}

In autogamous paramecia, the crescent stage micronuclei and those undergoing meiotic divisions were ultrastructurally the same as those observed during conjugation.

\section{DISCUSSION}

In all phases of the life cycle of $\boldsymbol{P}$. aurelia, the micronuclei contained numerous microtubules, but the way in which these were arranged depended on the phase of division. In the interphase micronuclei of vegetative cells, bundles of microtubules are always present in somewhat irregular sheets beneath the nuclear membrane (Jurand \& Selman, 1969, 1970), and these probably act as storage of partly polymerized tubulin. In the meta- and anaphase stages of the mitotic and meiotic divisions, the microtubules formed the spindle. In the telophase of the mitotic division, the interzonal microtubules of the spindle formed a cylindrical bundle of tightly packed microtubules filling a long isthmus bounded by the nuclear envelope: this isthmus connects the future daughter nuclei (Jurand \& Selman, 1969, 1970; Stevenson \& Lloyd, 1971).

In crescent stage micronuclei, the microtubules occupied a distinctive position just under the nuclear envelope, as has been reported by Stevenson (1972), and probably serve as endoskeletal elements. The fine threads, observed by Jones (1956) using light microscopy, in micronuclei of this stage might have been sheets of microtubules or, perhaps more likely, the longitudinal folds of the nuclear envelope.

The electron-dense spherical structures found at one end of the crescent stage micronuclei might be the organizing centres for the large number of microtubules found in these nuclei since no other structures are present which could have this function. These structures might correspond to the X-bodies of Jones (1956).

In the migratory and the stationary gamete pronuclei, microtubules were distributed randomly throughout the nucleoplasm. Micrographs of gamete pronuclei during the nuclear exchange in Paramecium multimicronucleatum, obtained by Inaba et al. (1966), indicate that microtubules are present in the nucleoplasm though it is difficult to be sure from the low magnification micrographs that the visible fibres are microtubular in nature. The same is true for a micrograph published by Schneider (1963) in a study of conjugation in P. aurelia. In Paramecium caudatum, however, gamete pronuclei are markedly different appearing

All bar markers represent I $\mu \mathrm{m}$. Fixative used was $1 \%(\mathrm{w} / \mathrm{v})$ osmium tetroxide.

Fig. 7. Low-power micrograph showing a micronucleus in the prophase of the second meiotic division $5 \mathrm{~h}$ after the beginning of conjugation. Note the three major condensed chromatin masses and microtubules situated mainly in the outer region of the nucleoplasm.

Fig. 8. Micronucleus at the metaphase of the second meiotic division $5 \frac{3}{4} \mathrm{~h}$ after the beginning of conjugation. Note the spindle shape of the micronucleus.

Fig. 9. Dumbbell-shaped micronucleus at the late anaphase of the second meiotic division with the meiotic spindle and both anaphase groups. In the lower part of the micrograph the fusion area of the paired ventral surfaces of the two conjugants is shown.

Fig. 10. Transverse section through a metaphase or anaphase micronucleus showing numerous chromosomes scattered throughout the whole interior. Between chromosomes there are many transversely-sectioned spindle microtubules which, at this magnification, appear as dots rather than circular profiles. 

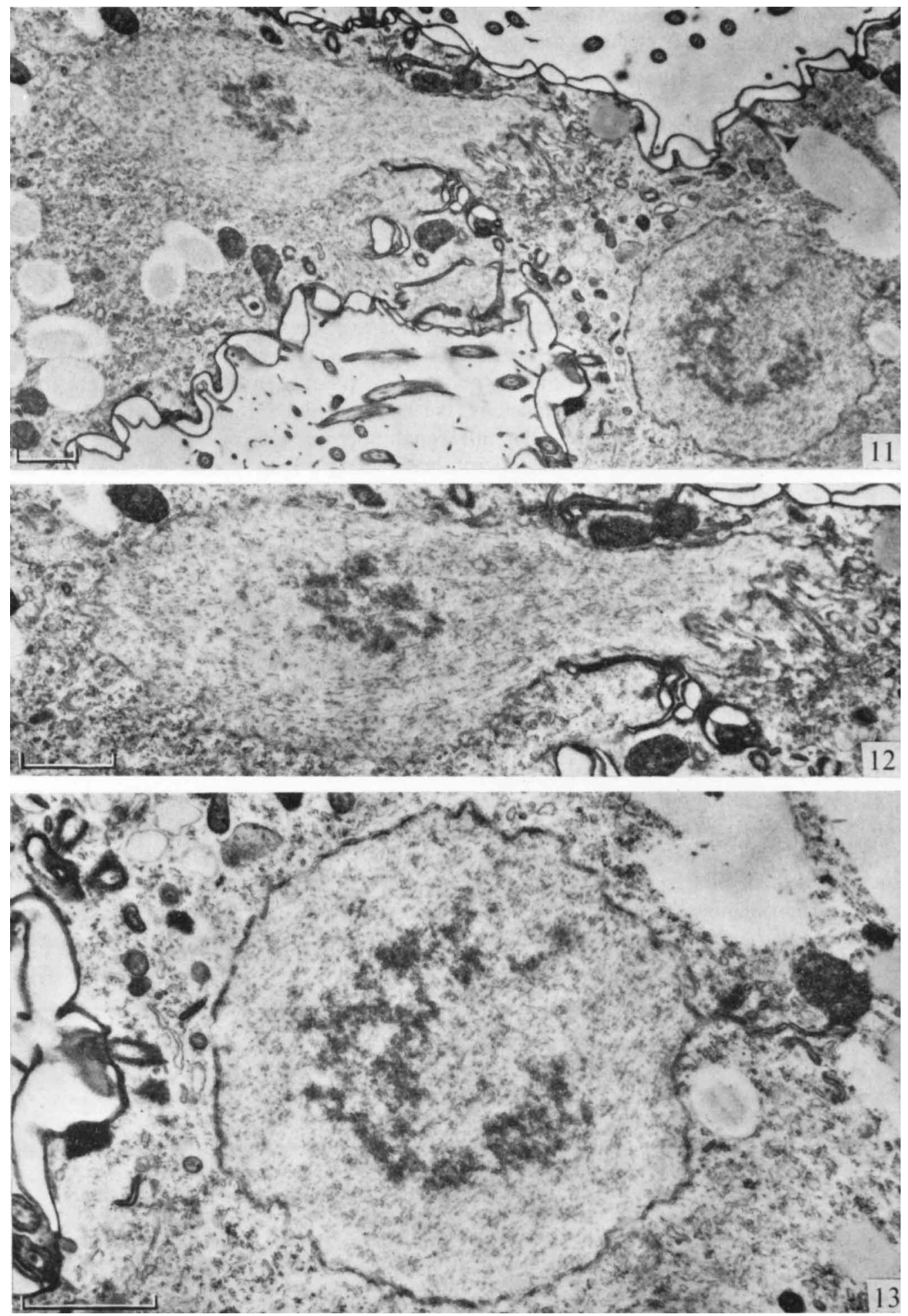

Figs. II-I 3. For legend see facing page. 
amoeboid, virtually homogeneous inside and without any indication of microtubules (André \& Vivier, 1962).

The average diameter of the microtubules of the crescent stage of meiotic prophase micronuclei was $24 \mathrm{~nm}$. In vegetative interphase micronuclei and in gamete pronuclei the diameter was 20 to $22 \mathrm{~nm}$, and in mitotic and meiotic spindles microtubules were even smaller, 18 to $20 \mathrm{~nm}$. These diameters are within the range of microtubule sizes reviewed by Olmsted \& Borisy (1973). The differences in diameter in the different forms of micronuclei possibly indicate that, during transition from one stage to the next, depolymerization and repolymerization of microtubular subunits occurs (Stevenson, 1972) and that microtubules have different functions at different stages of micronuclear ontogeny.

Except for the spherical electron-dense structures in crescent stage micronuclei, no proper centrioles have been found in any of the later forms of the meiotic micronuclei or in vegetative cells. Thus it appears that in $P$. aurelia centrioles are not essential as initiation sites for microtubular assembly. The role of initiator could possibly be played by kinetochores, as was found to be the case in grasshopper spermatocytes (Brinkley \& Nicklas, 1968).

The nature of the driving force in migration of the male pronucleus and whether it is an active or passive movement is not known (Vivier, 1974). Figure I I suggests that the pseudopodia were formed at the rear end of the migratory pronucleus because the pellicular edges round the cytoplasmic bridge were invaginated in a particular direction, probably the direction of the migration movement. In the cytoplasm, the migratory pronuclei were surrounded by microtubules, which occurred singly or in small bundles. The function of these microtubules is unknown, but it is tempting to suggest that they are instrumental, together with pseudopodia, in providing the support for a sliding movement of the migratory pronuclei. This suggestion appears more probable because the stationary pronuclei are not surrounded by microtubules. Sabnis \& Jacobs (1967) arrived at a similar conclusion in their work on the marine alga Caulerpa prolifera. Association of movement of interphase nuclei with cytoplasmic microtubules was also shown by Holmes \& Choppin (1968) in syncytia of hamster kidney cells induced by parainfluenza virus SVS. Similar movement associated with microtubules has been described for melanin granules (Bikle, Tilney \& Porter, 1966), cytoplasmic granules through the axopods in Actinospherium (Tilney, 1971), cytoplasmic organelles in Paramecium bursaria and tentacles of Podophrya parameciorum (Jurand \& Bomford, 1965). The presence of cytoplasmic microtubules in the vicinity of gamete pronuclei has not been reported previously, although it might be indicated in the micrograph published by Inaba et al. (I966).

The author thanks Professor J. R. Preer, Jr, for the use of research facilities in the Department of Zoology, of Indiana University, U.S.A., where part of this work was done. Thanks

All bar markers represent I $\mu \mathrm{m}$. Fixative used was I $\%(w / v)$ osmium tetroxide.

Fig. II. Paroral junction between two conjugants during the nuclear exchange $6 \frac{1}{2}$ hours after the beginning of conjugation. On the left is the migratory pronucleus with its greater part in the partner on the left. The rear end of the migratory pronucleus shows a pseudopodial region. Note that the edges of the fused pellicle round the opening on both sides are bent and directed towards the partner on the left indicating the direction of the migratory movement. On the right there is another pronucleus, probably the stationary one.

Fig. I2. The same migratory pronucleus as in Fig. I I at higher magnification. Note the microtubules oriented parallel to each other and parallel to the long axis and to the direction of movement. In the middle there is a loose accumulation of the condensed chromatin.

Fig. 13. The same pronucleus as on the right side of the Fig. I I at higher magnification. Note that in the surrounding cytoplasm there is no indication of microtubules or microfilaments. 

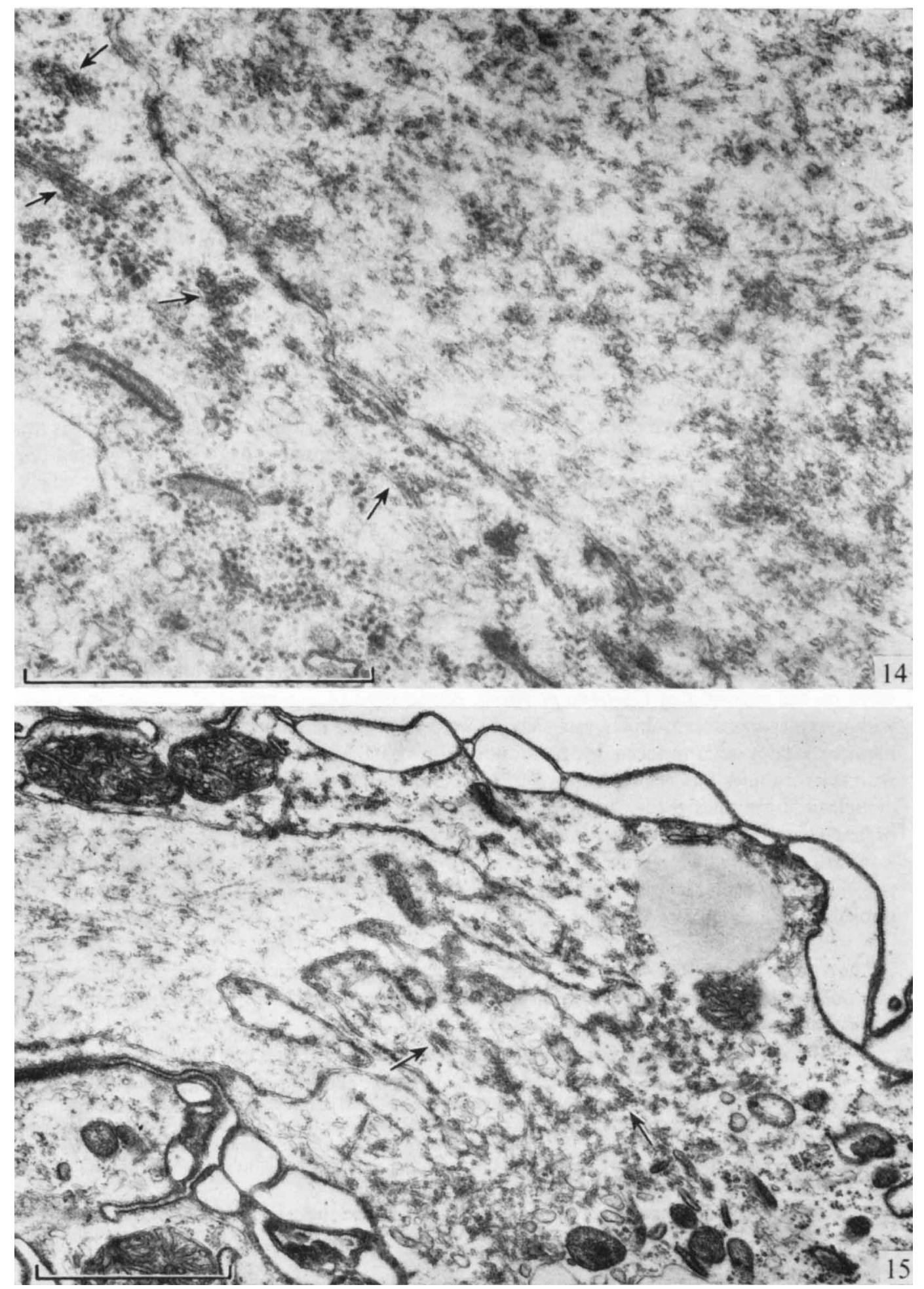

All bar markers represent $\mathrm{I} \mu \mathrm{m}$. Fixative used was $\mathrm{I} \%(\mathrm{w} / \mathrm{v})$ osmium tetroxide.

Fig. 14. A section of a gamete pronucleus (upper right) and of the adjacent cytoplasm (lower left) at high magnification. The nuclear envelope runs from top left to bottom right. Note the numerous single microtubules scattered in the nucleoplasm (unmarked) and bundles of microtubules in the adjacent cytoplasm (arrowed).

Fig. 15. A serial section to that in Figs. I I to 13, at higher magnification, showing formation of pseudopodia at the rear end of the migratory pronucleus. In the adjacent cytoplasm there are bundles of microtubules (arrowed) 
are also due to Professor Preer and to Dr. G. G. Selman for reading and discussing the manuscript, to Miss Helen Tait for her technical assistance, to Mr F. M. Johnston for printing the micrographs, and especially to $\mathrm{Mr} \mathrm{E}$. D. Roberts for the skilful reconstruction (Fig. 6) drawn after consulting numerous micrographs.

This paper is dedicated to Professor T. M. Sonneborn on his 70 th birthday.

\section{REFERENCES}

ANDRÉ, J. \& VIVIER, E. (I962). Quelques aspects ultrastructurales de l'échange micronucléaire lors de la conjugaison chez Paramecium caudatum. Journal of Ultrastructure Research 6, 390-406.

Bikle, D., Tilney, L. G. \& PORTER, K. R. (I966). Microtubules and pigment migration in the melanophores of Fundulus heteroclitus L. Protoplasma 6r, 322-345.

BrINKLEY, B. R. \& NICKLAS, R. B. (I968). Ultrastructure of meiotic spindle of grasshopper spermatocytes after chromosome micromanipulation. Journal of Cell Biology 39, I6a-17a.

DIRKSEN, E. R. \& CROCKER, T. T. (1966). Centriole replication in differentiating ciliated cells of mammalian respiratory epithelium. Journal de Microscopie 5, 629-644.

DRYL, S. (1959). Antigenic transformation in Paramecium aurelia after homologous antiserum treatment during autogamy and conjugation. Journal of Protozoology 6, S25.

HOLMES, K. V. \& CHOPPIN, P. W. (I968). On the role of microtubules in movement and alignment of nuclei in virus-induced syncytia. Journal of Cell Biology 39, 526-543.

INABA, F. \& KUDO, N. (1972). Electron microscopy of the nuclear events during binary fission in Paramecium multimicronucleatum. Journal of Protozoology 19, 57-63.

InABa, F., Imamoto, K. \& Suganuma, Y. (1966). Electron microscope observations on nuclear exchange during conjugation in Paramecium multimicronucleatum. Proceedings of the Japan Academy 42, 394-398.

Jones, K. W. (1956). Nuclear differentiation in Paramecium. Ph.D. thesis, University College Wales, Aberystwyth.

JURAND, A. \& Bomford, R. (I965). The fine structure of the parasitic suctorian Podophrya parameciorum. Journal de Microscopie 5, 509-522.

JURAND, A. \& IRELAND, M. J. (I965). A slow rotary shaker for embedding in viscous media. Stain Technology 40, 233-234.

Jurand, A. \& Selman, G. G. (1969). The Anatomy of Paramecium aurelia. London: Macmillan.

JURAND, A. \& SElman, G. G. (I970). Ultrastructure of the nuclei and intranuclear microtubules of Paramecium aurelia. Journal of General Microbiology 60, 357-364.

OLMSTED, J. B. \& BoRISY, G. G. (I973). Microtubules. Annual Review of Biochemistry 42, 507-540.

REYNOLDS, E. S. (1963). The use of lead citrate at high $\mathrm{pH}$ as an electron-opaque stain in electron microscopy. Journal of Cell Biology 17, 208-213.

RoBERTs, K. (1974). Cytoplasmic microtubules and their functions. In Progress in Biophysics and Molecular Biology, vol. 28, pp. 37I-402. Edited by J. A. V. Butler and D. Nobel. Oxford: Pergamon.

SABNIS, D. D. \& J JCOBS, W. P. (1967). Cytoplasmic streaming and microtubules in coenocytic marine alga Caulerpa prolifera. Journal of Cell Science 2, 465-472.

SCHNEIDER, L. (1963). Elektronenmikroskopische Untersuchungen der Konjugation von Paramecium. I. Die Auflösung und Neubildung der Zellmembran bei den Konjuganten. Protoplasma 56, I09-I40.

Stevenson, I. (1972). Ultrastructure of nuclear division in Paramecium aurelia. III. Meiosis in the micronucleus during conjugation. Australian Journal of Biological Sciences 25, 775-799.

SteVENSON, I. \& LLOYD, F. P. (197I). Ultrastructure of nuclear division in Paramecium aurelia. I. Mitosis in micronucleus. Australian Journal of Biological Sciences 24, 963-975.

TILNEY, L. G. (I97I). Origin and continuity of microtubules. In Origin and Continuity of Cell Organelles, pp. 222-260. Edited by J. Reinert and H. Ursprung. Berlin: Springer Verlag.

VIVIER, E. (1974). Morphology, taxonomy and general biology of the genus Paramecium. In ParameciumA Current Survey, pp. I-89. Edited by W. J. van Wagtendonk. Amsterdam: Elsevier.

VIVIER, E. \& ANDRÉ, J. (I96I). Données structurales et ultrastructurales nouvelles sur la conjugaison de Paramecium caudatum. Journal of Protozoology 8, 416-426. 